\title{
Astudy of anti-plaque efficacy and taste perception of Calendula officinalis mouth rinse
}

\author{
Erry Mochamad Arief ${ }^{1^{*}}$, Zaridah Zainal Abidin ${ }^{1}$, Mohaideen Sitheeque ${ }^{2}$, Md Azman \\ PKM Seeni Mohamad ${ }^{3}$
}

\author{
1Department of Periodontics, School of Dental Sciences Universiti Sains Malaysia, Malaysia \\ ${ }^{2}$ Department of Oral Medicine, School of Dental Sciences Universiti Sains Malaysia, Malaysia \\ ${ }^{3}$ Department of Craniofacial and Oral Biology, School of Dental Sciences Universiti Sains Malaysia, \\ Malaysia
}

\begin{abstract}
Introduction: An ideal mouth rinse must have an acceptable taste and very efficient antiplaque activity. Herbal mouth rinse (Plandula $®$ ), containing extracts of Calendula officinalis and other specified herbs, is widely cultivated as a herb. It is a remarkable healing agent and even useful to act as homeopathic remedies. Previous studies have compared this product with placebo; however, comparison against chlorhexidine have not been conducted thus far. Aim of this research was to analyse the efficacy of Calendula in Plandula ${ }^{\circledR}$ for controlling dental plaque and the acceptability of its taste in comparison with chlorhexidine. Methods: A double-blind, 3-day plaque regrowth, crossover, clinical study was conducted towards 16 volunteers participated in two periods, three days each, with modified oral hygiene practices through an intervening washout period of 4 days. At the commencement of each period, the participants received oral prophylaxis. They used the allocated mouth rinse and brushed teeth without toothpaste in all of the tooth surfaces, except palatal and lingual over three days. On the fourth day, the subjects were returned for plaque index measurement only on the palatal and lingual surfaces by the Quigley Hein index (modified by Turesky). The participants rinsed with $10 \mathrm{ml}$ of allocated mouth rinse three times daily for 30 seconds after tooth brushing. The participants followed the same steps during the second period using the alternate mouth rinse. They were also asked to taste both mouth rinses and evaluate with a Visual Analogue Scale (VAS). Results: Median plaque score for Plandula ${ }^{\circledR}$ mouth rinse was slightly higher compared to chlorhexidine but not statistically significant, with the $p$-value $=0.636(p>0.05)$. The mean VAS scale score for Plandula ${ }^{\circledR}$ taste perception was lower than the chlorhexidine, and statistically significant ( $p$-value $=0.01 ; p<0.05)$. Conclusion: Plandula ${ }^{\circledR}$ mouth rinse that contain calendula officinalis comparable with chlorhexidine in controlling dental plaque accumulation, with an acceptable taste.
\end{abstract}

Keywords: Calendula officinalis, chlorhexidine, plaque regrowth, taste perception.

p-ISSN: 1979-0201; e-ISSN: 2549-6212; Available from: http://jurnal.unpad.ac.id/pjd/article/view/29402

DOI: 10.24198 /pjd.vol32no3.29402

Submission: Sep 10, 2020; Accepted: Nov 25, 2020; Published online: Nov 30, 2020

"Corresponding author: Erry Mochamad Arief, Department of Periodontics, School of Dental Sciences Universiti Sains Malaysia, Malaysia. Health Campus, Universiti Sains Malaysia, Kubang Kerian, Kelantan, Malaysia, 16150. Phone: +60133269785; Email: erry@usm.my 


\section{INTRODUCTION}

The biofilm in the oral cavity known as a bacterial plaque contains of complex organised microbial community is formed naturally on the exposed surface of teeth. The metabolism and colonisation of bacteria is in fact the primary cause of dental caries $^{1}$, gingivitis, periodontitis ${ }^{2}$, peri-implant infections $^{3}$ and stomatitis ${ }^{4,5}$ condition caused by bacterial plaque can be controlled by means of mechanical or chemical. The use of mouth rinse as a cleansing chemical agent, ideally due to its ability to reach all the surface of teeth. It can be from a very simple aqueous solution to a very complex with addition of flavor, colour or any other additives to make it acceptable in the general population. ${ }^{6}$

Nowadays, mouth rinse was formulated with antimicrobial. Broad-spectrum antimicrobials, such as chlorhexidine, essential oils, and cetylpyridinium chloride (CPC), are commonly formulated in mouth rinses. Chlorhexidine, with formula $\mathrm{C}_{22} \mathrm{H}_{30} \mathrm{Cl}_{2} \mathrm{~N}_{10}$ is still considered a gold standard mouthrinse with the ability to reduce plaque successfully. ${ }^{7}$ Based on a clinical study conducted by Welk et al. ${ }^{8}, 0.12 \%$ has significantly better in reducing plaque compared to polyhexamethane biguanide (PHMB) but has no significant different with triclosan. However, chlorhexidine is well known for the extrinsic staining as the long-term effect. ${ }^{9}$

Based on today scenario, people now related both their oral health and overall medical health. In response to that many personal mouth rinse have been marketed to offer variety of natural mouth rinse to help consumer realise and maintain their whole-body health without artificial pharmaceutical. Modern society nowadays realises that natural-based mouth rinse, such as lime peel essential oil-based mouth rinse is relatively safer to use for a long term period on a daily basis. ${ }^{10}$

Calendula officinalis is the experimental sample in this study, is widely cultivated as a herb it is a remarkable healing agent and even useful to act as homeopathic remedies. Its extract has been used in Europe since before the $12^{\text {th }}$ century primarily as a topical antiinflammatory agent. ${ }^{11}$ Recently, any thesis reviewed about the effectiveness off Plandula ${ }^{\circledR}$ mouthrinse containing the extract of Calendula officinalis, provide a significant benefit in reducing plaque and gingival inflammation. ${ }^{5} \mathrm{An}$ in vitro study done by Haffajee et al. $^{12}$, showed that the herbal mouthrinse containing extract of Calendula officinalis were effective in inhibiting oral bacteria thereby it is reflecting its usefulness in reducing plaque and gingival inflammation although less potent than the chlorhexidine. ${ }^{12}$

The purpose of the present study was to compare plaque reducing efficacy and taste perception between Plandula ${ }^{\circledR}$ mouthrinse containing extract of $0.64 \%$ Calendula officinalis and Difflam-C containing $0.12 \%$ chlorhexidine.

\section{METHODS}

Sixteen volunteers, 12 males and 4 females were participated, with a mean age of 28 years old. They received a written explanation of the background of the study, its objectives and their involvement (Figure 1).

The participants were required to fulfill the following criteria's such as aged between $23-48$ years-old, minimum of 25 scorable tooth (with no restoration on lingual and palatal surfaces, partial dentures, orthodontic banding or wires) and participants with healthy oral and periodontal condition with clinical parameter were bleeding on probing (BOP) $\leq 10 \%$ and probing depth $\leq 3 \mathrm{~mm}$ and tooth mobility <grade 1. In addition, participants allergic to any of the mouthrinse components or on any antibiotic, pregnant, with systemic diseases such as diabetes and any adverse medical history or long-term medication were excluded from the study.

All participants who fulfill the criteria were signing an informed consent prior to the study. The ethical for the present study was approved by the School of Medical Sciences Universiti Sains Malaysia Ethics Committee with the approval number of (USMKK/PPP/JEPeM (224.4.(3.10)).

This clinical trial was a double blind, crossover, randomised, consisting of two periods intervention, each period was 3-days duration that were separated by 4-days washout period. Two different mouthrinse were compared (Figure 2): Mouthrinse A: Plandula ${ }^{\circledR}$ mouthrinse containing the extract of Calendula officinalis $(0.64 \%)$ (Figure 3); Mouthrinse B: Difflam-C containing chlorhexidine gluconate $(0.12 \%)$ (Figure 4$)$. 


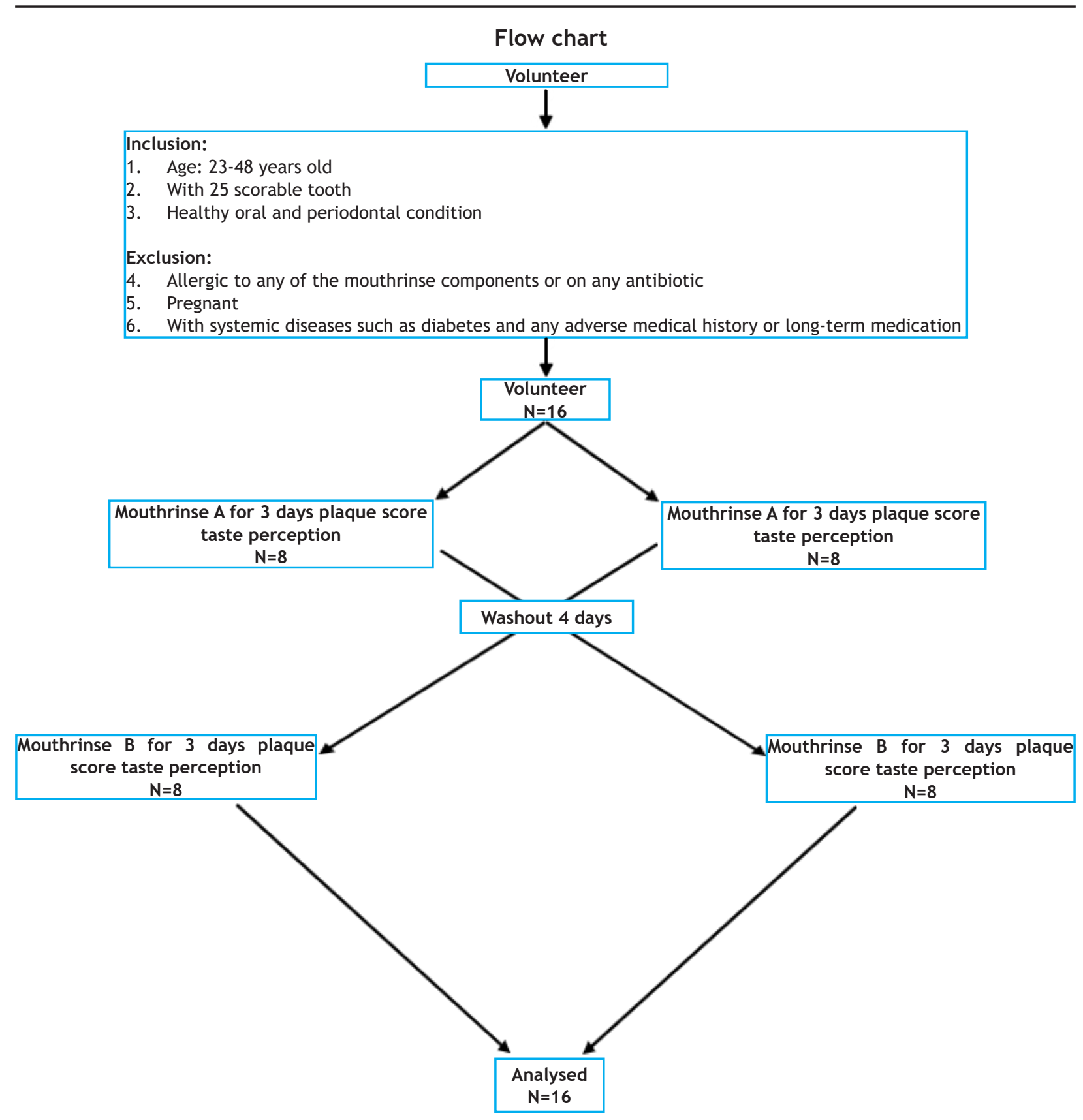

Figure 1 . The study flow chart

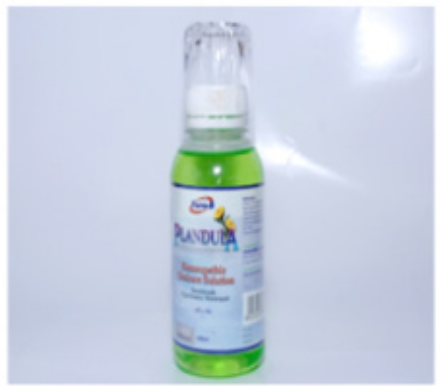

Figure 2. Mouth rinse A: Plandula ${ }^{\circledR}$ mouthrinse containing the extract of Calendula officinalis $(0.64 \%)$

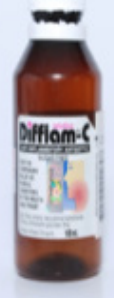

Figure 3. Mouth rinses B : Difflam C

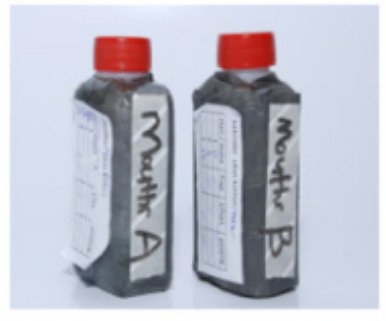

Figure 4. Mouthrinse A and B (bottles were covered with the black plastic and were kept in the same kind of bottle) 


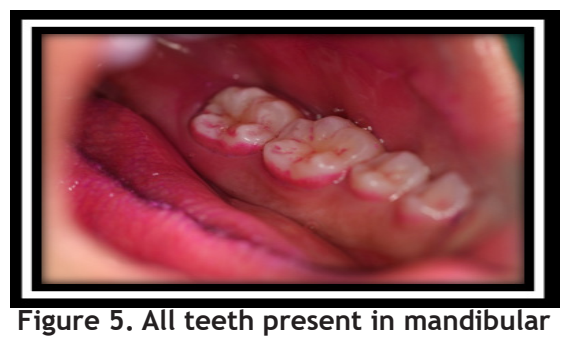

were assessed except $3^{\text {rd }}$ molars

Due to the double-blind design, all bottles were covered with the black plastic and were kept in the same kind of bottle (Figure 4). Two dental surgery assistances were included to assist along the study. The assessor and the participant did not know the allocated mouthrinse until completion of the study. At the baseline, of each test period, all participants received a dental prophylaxis to remove plaque, calculus and stain from all tooth surfaces to make plaque become zero. They were randomly assigned to the allocated mouthrinse. All participants were randomised for 2 different allocated mouthrinse using randomisation plan generator. ${ }^{13}$

The instruction for the allocated mouthrinse was given to all participants at the chairside. All participants were instructed to use $10 \mathrm{ml}$ of allocated mouthrinse for 30 second three times daily which was done after brushing their teeth, in the morning after breakfast, once in the afternoon after lunch and once at night, before they went to sleep. The toothbrushing was done without toothpaste on buccal/facial and occlusal only. During the each of test period, all participants were instructed to refrain from using any other oral hygiene procedure. On the fourth day, the participants returned for measurement of plaque on the palatal and lingual surfaces by Quigley Hein Index (modified by Turesky) (Figure 5 and 6$)^{9}$.

Plaque was assessed then, and all the measurement was done by an examiner who was blinded to the allocated mouthrinse. Following the measurement, another dental prophylaxis was done for all teeth. At the end of first test period, the allocated mouthrinses were collected. To check for compliance, the participants were asked to tick the time of use of the mouthrinse onto a calendar record chart. After that, all participants entered a 4-day washout phase to minimize carry-over effects and habitual oral hygiene procedures were resumed. The second period of

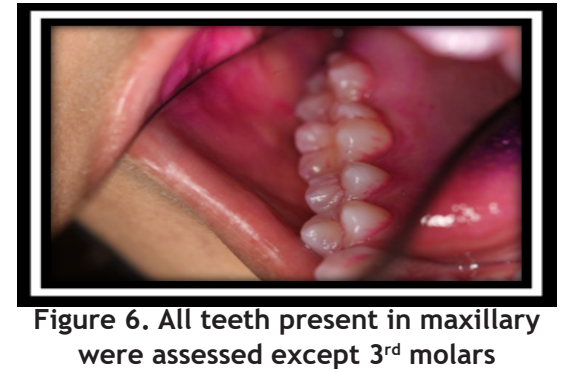

another 3 days commenced after an intervening 4-day washout period. The same procedures were prescribed to the participants but using the other allocated mouthrinse. They were also asked to taste both mouthrinses and evaluated them on a Visual Analogue Scale (VAS) of 0 to 10,0 being plain taste and 10 for bitter taste. The reproductivity was assessed before start of study, in a total of 110 surfaces from one participant, the plaque scorewas taken twice and repeated at 90 minutes after. The difference in repeated recording of $0, \pm$ $1, \pm 2$ was calculated. Level of reproducibility was set at $80 \%$ agreement.

\section{Statistical analysis}

Statistical analysis was carried out using the statistical package for social science system (SPSS) version 18. Calculation was performed based on percentage of agreement ( 0 and 1$)$. Level of reproducibility was set at the $80 \%$ agreement. Comparison between test (Plandula $®$ ) and Chlorhexidine groups, Paired sample t-test was employed where the significance level was at the level $p \leq 0.05$.

\section{RESULTS}

Demographic characteristic of the participants is presented in Table 1 . The reproducibility results were shown a total of 90 out of 110 surface had 0 score repeated recordingg, which gave the percentage of $82 \%$ (Table 2). Thus, the reproducibility percentage agreement of above $80 \%$ was achieved. All participants were shown compliance to the instruction and no adverse effect were reported during this study. No significant difference noticed in the plaque scores between Calendula officinalis and chlorhexidine mouth rinse, whereas, significant difference noticed for the taste perception between both mouth rinses (Table 3). 


\begin{tabular}{|c|c|}
\hline \multicolumn{2}{|l|}{ Participants characteristics $(n=16)$} \\
\hline Age: range, mean & $20-50,28$ years old \\
\hline \multicolumn{2}{|l|}{ Gender, n (\%) } \\
\hline Male & 12 \\
\hline Female & 4 \\
\hline \multicolumn{2}{|l|}{ Scorable tooth } \\
\hline$\geq 25$ tooth & $100 \%$ \\
\hline$<25$ tooth & $0 \%$ \\
\hline \multicolumn{2}{|l|}{ Bleeding on probing (\%) } \\
\hline$\leq 10 \%$ & $100 \%$ \\
\hline$>10 \%$ & $0 \%$ \\
\hline \multicolumn{2}{|l|}{ Pocket depth (\%) } \\
\hline$\leq 3 \mathrm{~mm}$ & $100 \%$ \\
\hline$>3 \mathrm{~mm}$ & $0 \%$ \\
\hline $\begin{array}{l}\text { Allergic to any of the mouthrinse } \\
\text { components or on any antibiotic }\end{array}$ & $0 \%$ \\
\hline Pregnant & $0 \%$ \\
\hline $\begin{array}{l}\text { With systemic diseases such as } \\
\text { diabetes and any adverse medical } \\
\text { history or long-term medication }\end{array}$ & $0 \%$ \\
\hline
\end{tabular}

Table 2. Reproducibility

\begin{tabular}{lcc}
\hline $\begin{array}{c}\text { Difference } \\
\text { between repeated } \\
\text { recordings }\end{array}$ & Number of surfaces & Percentages \\
\hline 0 & 90 & 81.8 \\
\pm 1 & 20 & 18.2 \\
Total & 110 & 100 \\
\hline $\begin{array}{l}0=\text { no different, 1 = different } \geq 1 \text {; Calculation based on } \\
\text { percentage; Level of reproducibility was set at } 80 \% \\
\text { agreement }\end{array}$
\end{tabular}

Table 3. The mean (SD) of plaque index and taste perception

\begin{tabular}{cccc}
\hline Group & N & $\begin{array}{c}\text { Mean plaque } \\
\text { index (SD) }\end{array}$ & $\begin{array}{c}\text { Taste } \\
\text { perception* }\end{array}$ \\
\hline $\begin{array}{c}\text { Plandula } \\
\text { mouthrinse }\end{array}$ & 16 & $1.66(0.54)$ & $3.00(1.21)$ \\
$\begin{array}{c}\text { Chlorhexidine } \\
\text { mouthrinse } \\
\text { p-value }\end{array}$ & 16 & $1.43(0.52)$ & $6.81(1.51)$ \\
& & 0.636 & 0.01
\end{tabular}

Paired sample t-test was employed where the significance level was at the level $p \leq 0.05$; *Statistically significantly different

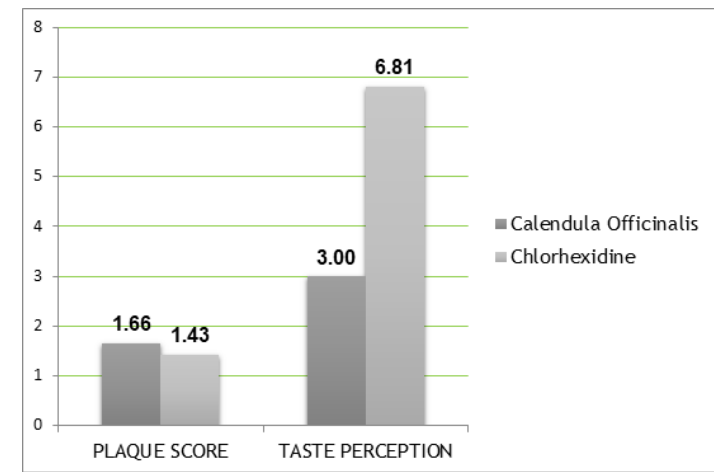

Figure 7. The mean of plaque score and taste perception

\section{DISCUSSION}

This study was assessing the 3 -days plaque regrowth model in evaluating the plaque inhibitory effect of Plandula ${ }^{\circledR}$ mouthrinse and taste perception between Plandula ${ }^{\circledR}$ mouthrinse containing extract of $0.64 \%$ Calendula officinalis and Difflam - C containing $0.12 \%$ chlorhexidine. The methods that was used in this were adopted from various study before. Many studies previously have used 3 day - plaque regrowth model to assess various effect of mouthrinse and this period is enough to allow plaque to accumulate freely. A study done by Simonsson et al. ${ }^{15}$, compared heavy and light plaque formers which eventually result in a large difference based on several factors.

In this study, the plaque index was assessed with Quigley and Hein, modified by Turesky ${ }^{9}$ which is reliable and also sensitive in term of more criteria or differentiation at cervical area, from only 1 criteria in Plaque Index ${ }^{16}$ to 3 criteria in Quigley and Hein, modified by Turesky ${ }^{9}$, thus, it is more accurate to assess the cervical area covered by plaque. ${ }^{16}$ In this study results shown that no significant difference noticed in the plaque scores between Calendula officinalis and chlorhexidine. Yusoff ${ }^{17}$ compared mouthrinse containing the extract of Calendula officinalis with the plain water result in the significant plaque reducing efficacy. Apart from that, a research of herbal rinse by Haffajee et al. ${ }^{12}$ containing extract of Calendula officinalis showed it was more effective than the essential oil rinse in inhibiting the growth of oral bacteria in vitro although it is less potent than the chlorhexidine.

This result is also supported by our findings on efficacy of Calendula officinalis. In this study shown there was significant difference noticed for the taste perception between both mouthrinses. The taste of mouthrinse containing the extract of Calendula officinalis were appreciated better maybe due to absence of alcohol. A study conducted by Van Strydonck et al. ${ }^{5}$ comparing a $0.12 \%$ chlorhexidine free alcohol and $0.2 \%$ chlorhexidine containing of $11.8 \%$ ethanol showed a significant different, which was better taste acceptability for non-alcohol. Similarly, a study of Ernst et al. ${ }^{18}$, suggested that approximately of $33 \%$ participants claimed that the alcohol-contained chlorhexidine has a poor taste. This was in 
agreement with our findings on taste perception of Calendula officinalis. So our suggestion for better taste, mouthrinse should not contain an alcohol. Certain limitations were noted. The colour and taste could not be similar. The chemicals of both mouthrinse were neither added nor modified as this could change or affect the therapeutic value of respective mouthrinse. In order to minimize the limitation, the bottles were covered with black plastic and the taste of chemicals are different, this may provoke participants towards the acceptability of certain mouthrinse that may later affect the compliance which consequently affect in the result.

As this matter being brought, all participants were reminded to follow the standardisation from the beginning and the incompliance were considered as dropout. Rinsing calendar were glued together to check the compliance and instruction were sent prior to each appointment. Another limitation is smal amount of participants were taken due to time restriction and some difficulty to get more participants. All participants were screened to pass the criteria listed. Initially, there were more than two participants were eliminated during the screening following the exclusion protocol.

The participant also came only from one source, which was the patients who attend the Universiti Sains Malaya Hospital, and might not consider representing the general population. However, the participants were randomly selected from the age of 23-48 years old to reduce the conscious bias and to minimise the unconscious bias for unknown factor. ${ }^{1}$ Other limitation was the Hawthorne effect, that the participants tend to rinse more than daily practice.

A crossover design of this study also made it possible to create a carry over effect, which must always be considered especially if an antimicrobial agent is applied. It is important for the participants to returned to their original status before proceeding to the next stage. This carry over effect can be overcome by providing a washout period of standard oral hygiene which is thought to be sufficient to neutralise the previous therapeutics effect. A longer washout period is preferable and design should be balanced for residual effects, at least from the preceding treatment period. ${ }^{14}$

\section{CONCLUSION}

Calendula in Plandula ${ }^{\circledR}$ mouth rinse containing $0.64 \%$ Calendula officinalis is more effective in inhibiting plaque formation, and it was comparable with $0.12 \%$ chlorhexidine mouth rinse. Plandula $\otimes$ also has a better taste compared to the chlorhexidine mouth rinse.

\section{ACKNOWLEDGMENT}

This study was supported by Farabi Herbal Industries Sdn. Bhd.

\section{REFERENCES}

1. Dani S, Prabhu A, Chaitra KR, Desai NC, Patil SR, Rajeev R. Assessment of Streptococcus mutans in healthy versus gingivitis and chronic periodontitis: A clinico-microbiological study. Contemp Clin Dent. 2016; 7(4): 529-34. DOI: 10.4103/0976-237X.194114

2. Teles R, Teles F, Frias-Lopez J, Paster B, Haffajee A. Lessons learned and unlearned in periodontal microbiology. Periodontol 2000. 2013; 62(1): 95-162. DOI: 10.1111/prd.12010

3. Teughels W, Van Assche N, Sliepen I, Quirynen M. Effect of material characteristics and/or surface topography on biofilm development. Clin Oral Implants Res. 2006; 17(Suppl 2): 6881. DOI: $10.1111 / j .1600-0501.2006 .01353 . x$

4. Irani S. Orofacial bacterial infectious diseases: An update. J Int Soc Prev Community Dent. 2017; 7(Suppl 2): S61-S67. DOI: 10.4103/ jispcd.JISPCD_290_17

5. Van Strydonck DAC, Timmerman MF, Van Der Velden U, Van Der Weijden GA. Plaque inhibition of two commercially available chlorhexidine mouthrinses. J Clin Periodontol. 2005; 32(3): 305-9. DOI: 10.1111/j.1600051X.2005.00681.x

6. Versteeg PA, Rosema NAM, Hoenderdos NL, Slot DE, Van Der Weijden GA. The plaque inhibitory effect of a CPC mouthrinse in a 3-day plaque accumulation model - A crossover study. Int J Dent Hyg. 2010; 8(4): 269-75. DOI: $10.1111 / j .1601-5037.2009 .00421 . x$ 
7. Balagopal S, Arjunkumar R. Chlorhexidine: The gold standard antiplaque agent. J Pharm Sci Res. 2013; 5(12): 270-4.

8. Welk A, Splieth $\mathrm{CH}$, Schmidt-Martens $\mathrm{G}$, Schwahn C, Kocher T, Kramer A, et al. The effect of a polyhexamethylene biguanide mouthrinse compared with a triclosan rinse and a chlorhexidine rinse on bacterial counts and 4-day plaque re-growth. J Clin Periodontol. 2005; 32(5): 499-505. DOI: 10.1111/j.1600051X.2005.00702.X

9. Moran J, Addy M, Newcombe R. A 4-day plaque regrowth study comparing an essential oil mouthrinse with a triclosan mouthrinse. J Clin Periodontol. 1997; 24(9 Pt 1): 636-9. DOI: 10.1111/j.1600-051x.1997.tb00241.x

10. Mulyanti S, Laela DS, Julaeha E, Suwargiani $A A$, Aripin D. Formulation of mouth rinse from the essential oils of lime (Citrus aurantifolia) and its inhibitory efficacy on the growth of Streptococcus mutans - in vitro. Padjadjaran J Dent. 2020; 32(1): 39-47. DOI: 10.24198/pjd. vol32no1.25486

11. Dona BL, Gründemann LJ, Steinfort J, Timmerman MF, Van Der Weijden GA. The inhibitory effect of combining chlorhexidine and hydrogen peroxide on 3-day plaque accumulation. J Clin Periodontol. 1998; 25(11 Pt 1): 879-83. DOI: 10.1111/j.1600-051x.1998. tb02385.x

12. Haffajee AD, Yaskell T, Socransky SS. Antimicrobial effectiveness of an herbal mouthrinse compared with an essential oil and a chlorhexidine mouthrinse. J Am Dent Assoc. 2008; 139(5): 606-11. DOI: 10.14219/ jada.archive.2008.0222

13. Kim J, Shin W. How to do random allocation (Randomization). Clin Ort Surg. 2014; 6(1): 103-9. DOI: 10.4055/cios.2014.6.1.103

14. Turesky S, Gilmore ND, Glickman I. Reduced plaque formation by the chloromethyl analogue of vitamin C. J Periodontol. 1970; 41(1): 41-3. DOI: 10.1902/jop.1970.41.41.41

15. Simonsson T, Ronstrom A, Rundegren J, Birkheb D. Rate of plaque formation - Some clinical and biochemical characteristics of "heavy" and "light" plaque formers. Eur J Oral Sci. 1987; 95(2): 97-103. DOI: 10.1111/j.16000722.1987.tb01814.x

16. Paraskevas S, Rosema NAF, Versteeg $P$, Timmerman MF, Van Der Velden U, Van Der Weijden GA. The additional effect of a dentifrice on the instant efficacy of toothbrushing: $A$ crossover study. J Periodontol. 2007; 78(6): 1011-6. DOI: 10.1902/jop.2007.060339

17. Yusoff S. The Effect of a Mouthwash Containing Extracts of Calendula officinalis on Plaque and Gingivitis. Kuala Lumpur: Jabatan Perubatan Mulut, Patologi dan Periodontologi, Fakulti Pergigian, Universiti Malaya; 2003.

18. Ernst CP, Prockl K, Willershausen B. The effectiveness and side effects of $0.1 \%$ and $0.2 \%$ chlorhexidine mouthrinses: A clinical study. Quintessence Int. 1998; 29(7): 443-8.

19. Newcombe RG, Addy M, McKeown S. Residual effect of chlorhexidine gluconate in 4-day plaque regrowth crossover trials, and its implications for study design. J Periodontal Res. 1995; 30(5): 319-24. DOI: 10.1111/j.16000765.1995.tb01282.x 